\title{
Commognitive Analysis Of Students' Errors In Solving High Order Thinking Skills Problems
}

\section{Lili Supardi $^{\mathrm{a}}$, Moh Zayyadi ${ }^{\mathrm{b} *}$, Harfin Lanya ${ }^{\mathrm{c}}$, Sri Indriati Hasanah ${ }^{\mathrm{d}}$, Septia Nur Hidayati ${ }^{\mathrm{e}}$}

${ }^{a}$ Madura University, Mathematics Education, Indonesia (ORCID: 0000-0001-6506-0862)

${ }^{b}$ Madura University, Mathematics Education, Indonesia (ORCID: 0000-0002-2621-7238)

${ }^{\mathrm{c}}$ Madura University, Mathematics Education, Indonesia (ORCID: 0000-0001-5653-785X)

${ }^{\mathrm{d}}$ Madura University, Mathematics Education, Indonesia (ORCID: 0000-0001-9430-0044)

eMadura University, Mathematics Education, Indonesia (ORCID: 0000-0001-8055-3438)

*Corresponding Author:email: zayyadi@unira.ac,id

Article History: Received: 11 January 2021; Accepted: 27 February 2021; Published online: 5 April 2021

\begin{abstract}
This study aims to describe the commognitive analysis of students' errors in solving High order thinking skills problems. The problem of this study is that students have difficulty of solving mathematical problems because students do not build their own knowledge of mathematical concepts but tend to memorize concepts so that when students solve math problems students often make mistakes and do not find solutions to solve these problems. Students also taught themselves that math is difficult. This type of research is a qualitative description. The research subjects were three grade X students of Senior High school 1 Pamekasan. The instruments used in this study were mathematical problem seets and semi-structured interviews. The results showed that students experienced faults in 1) word use (mistake writting mathematical symbol and not consisstent in writting naming. the factors are hasty, inaccurate, not understanding the questions, incomplete writing is known, and asked, not understanding the material.); 2) Visual mediator (mistakes in drawing or illustrating the problem. Student is not using visual mediators, some students use visual mediators but are still wrong and use it,); 3) Narrative (not writing the formula but writing the results directly. Student mistakes also occur because students do not know the strategy that will be used to solve them, while the students' mistakes made at this stage are: students are wrong in writing the formula definition sine and wrong for not writing the formula.); 4) Routine (inaccurate in arithmetic operations so that the final answer is wrong. The mistakes of some students in general in doing routine are the students doing wrong calculations, wrong in substituting values or numbers that are known in the formula.). With this research, teachers can find out where the difficulties and misconceptions of students are in doing it so that it becomes new learning for students to improve learning outcomes and minimize errors.
\end{abstract}

Keywords: commognitive, mathematical problems, High order thinking skills

\section{Introduction}

Mathematics is a basic science that is widely used in all fields of human life, even mathematics has been taught since elementary school students to college, this is important to do so that early on, students are required to recognize the basic concepts of mathematics. Sullivan (2011) states that Mathematics is not only a numeracy skill but mathematics also covers concepts and structures. In mathematics, all material previously studied has a relationship with each other as stated by Li \& Schoenfeld (2019) that mathematics is a structured science, with initial abilities being a prerequisite for subsequent abilities. So that the basic concepts of mathematics must be taught since elementary school because these basic concepts are used as a reference or guide for students in solving mathematical problems.

Mathematical problem solving becomes a very important thing to be instilled in students because problemsolving is able to develop students' thinking abilities (Saragih \& Habeahan, 2014). This is in agreement with Subanji (2015) that the field of mathematics is one of the fields of study that can encourage students to think. The ability to solve problems is the focus of schools at all levels (Hossain, 2015). Solving mathematical problems derived from mathematical problems in the form of a mathematical problem in which there needs to be a solution. There are two types of mathematical problem solving namely routine problem solving and nonroutine problem-solving (Sipayung \& Anzelina, 2019). Routine problem solving uses standard procedures known in mathematics (Kurniati and Zayyadi, 2018). Whereas the non-routine problem solving problem provided is an unusual problem situation and there is no definite standard to solve it.

Not all students are able to solve mathematical problems with correct problem solving, students sometimes have difficulty in solving mathematical problems. The difficulty of students in learning mathematics is because students do not build their own knowledge of mathematical concepts but tend to memorize mathematical concepts without knowing the meaning contained in these concepts so that when students solve mathematical problems students often make mistakes and do not find the solution to solve the problem (Acharya, 2017). The 
difficulty of learning mathematical students is not only caused by ineffective learning but may also be caused by differences in personality types possessed by each individual (Karimah, et al., 2018). Even though the basic concept of mathematics used to solve every mathematical problem has been learned since elementary school. As an example in trigonometry material, trigonometry is material found in high school but the basic concepts in working on trigonometry have existed since junior high schools such as the Pythagorean theorem, the concept of triangles and the basic concepts of rank and root shapes. There are five standards of mathematical material that must be studied from prekindergarten to Class XII, namely number and operation, algebra, geometry, measurement, data analysis, and probability (NCTM, 2000). Of the five mathematical standards geometry (the concept of Pythagoras) and measurement are the provisions of students in solving trigonometric problems so that if students do not master these basic concepts students will have difficulty in solving problems.

With indications of difficulties in solving problems experienced by students, it is necessary to have an analysis of errors made by students in the process of solving the most common mathematical problems on high order thinking skills trigonometry problems. High Order Thinking Skills (HOTS) is divided into four groups, namely problem solving, making decisions, critical thinking and creative thinking (Arif, 2019). While the process of solving the high order thinking skills problem is a process of thinking someone. Sfard (2018) assumes that thinking can be conceptualized as someone's communication with himself. Commognitive is a combination of the words communication and cognitive. This means that communication and thinking are two sides of one activity called commognition. Commognitive methodology analyzes students solving mathematical problems (Presmeg, 2016). Commognitive components consist of word use, visual mediator, narrative, and routine (Sfard, 2008, 2010; Zayyadi, et al, 2020). Word uses refers to ordinary words used in daily communication, but with unique and specific meanings in mathematics, such as differentiation, boundaries, and points (Sfard, 2007). Visual mediators are objects that look like symbols, graphs, and diagrams that participants use in mathematical discourse to identify objects into focus (Nardi, Ryve, Stadler, \& Viirman, 2014; Berger, 2013). The narrative is the sequence of text, oral or written, which is used as a description of objects that are labeled true or false. In mathematical discourse, the approved narrative is known as mathematical theory (Sfard, 2007; Zayyadi, et al, 2019). Routine is a combination of metarules that describe discursive actions (Sfard, 2008).

Error analysis of students in solving high order thinking skills trigonometry problems with commognitive is important to do because this can see the difficulty of students in solving problems not only with the final results obtained but also in word uses, visual mediators, narrative, and routines used. In this study, word use is words, symbols, mathematical symbols, naming information in pictures, which are used by students in the process of solving problems. Visual mediator is a sketch that is used by students in illustrating problems into pictures. Narrative is the formula used in solving problems and theorems used to solve problems. routine is the stage where students substitute the known into the formula or theorem that has been written. After that, the results of the error description are used to determine the location of students' difficulties in the process of solving problems so that in the future students are able to minimize errors.

\section{Method}

In accordance with the problems studied, this research is qualitative descriptive research because this study intends to describe the error analysis of students in solving high order thinking skills trigonometry. Descriptive research is a research method that seeks to describe and interpret objects according to what they are. This research was conducted online (via WhatsApp) with 3 subjects of class X students of SHS 1 Pamekasan, three subjects made mistakes in solving problems with the initials subject 1 , subject 2 , and subject 3 . The research instruments used to obtain research data were 1 ). Written test in the form of a math problem sheet 2) Semistructured interview guide. The problem sheet and the interview results are used as a guideline for researchers in bringing up the 4 framework commissions of students namely word use, visual mediators, narratives, and routines. The problem sheets given to students are as follows:

1. Ari and Budi are best friends. That night they were in their respective homes. The distance of their house is $2 \mathrm{~km}$. Adi sent a short message to Budi that he was standing facing the front of Budi's house and playing a green laser gun which was strong and fired at an elevation angle of $75^{\circ}$ into the cloud which is near the sky between the two houses so that it hit the cloud. Budi goes to stand in front of the house while observing the green point in the cloud using the kinometer and the angle formed $45^{\circ}$. Then the height of the cloud that is formed is ...

2. A ship sailing from port $A$ with a direction of 30 to port $B$ for 3 hours with a speed 50 miles/hour. Then the ship continue sailing west and stop until the position of the ship is perpendicular to port A. If the speed of the ship from port B is $100 \mathrm{miles} / \mathrm{hour}$, then the length of the ship's journey from port B to its current position is ... minutes.

Figure 1. High Order Thinking Skills Questions Given to Students 
Data collection techniques are the most strategic step in research because the main purpose of the research is to get data. Data collection techniques used in this study are (1) Collection of library data, which is looking for references related to cognitive; (2) field data collection, namely answers to questions belonging to the subject and the results of semi-structured interviews.

Activities in qualitative data analysis are carried out interactively and continue continuously until completion so that the data is already saturated. Activities in data analysis, namely data reduction, data display, and conclusion drawing/verification (Sugiyono, 2012). Data analysis in this study was conducted by 1) the process of data reduction, namely activities that refer to the process of compiling, selecting and simplifying the written test results and interviews, 2) presenting data where the researcher will show the data in the form of a description to give a picture of a neatly arranged set of information, and organized so that it is possible to draw conclusions from the data. 3) Draw conclusions, namely the activity of summarizing data and checking the truth of the data.

\section{Results}

This study uses cognitive recognition in which each subject error in solving problems is adjusted to the four cognitive frameworks according to Sfard (2018), namely word use, visual mediator, narrative, and routine.

\subsection{Problem 1}

\subsubsection{Subject $1(\mathrm{~S} 1)$}

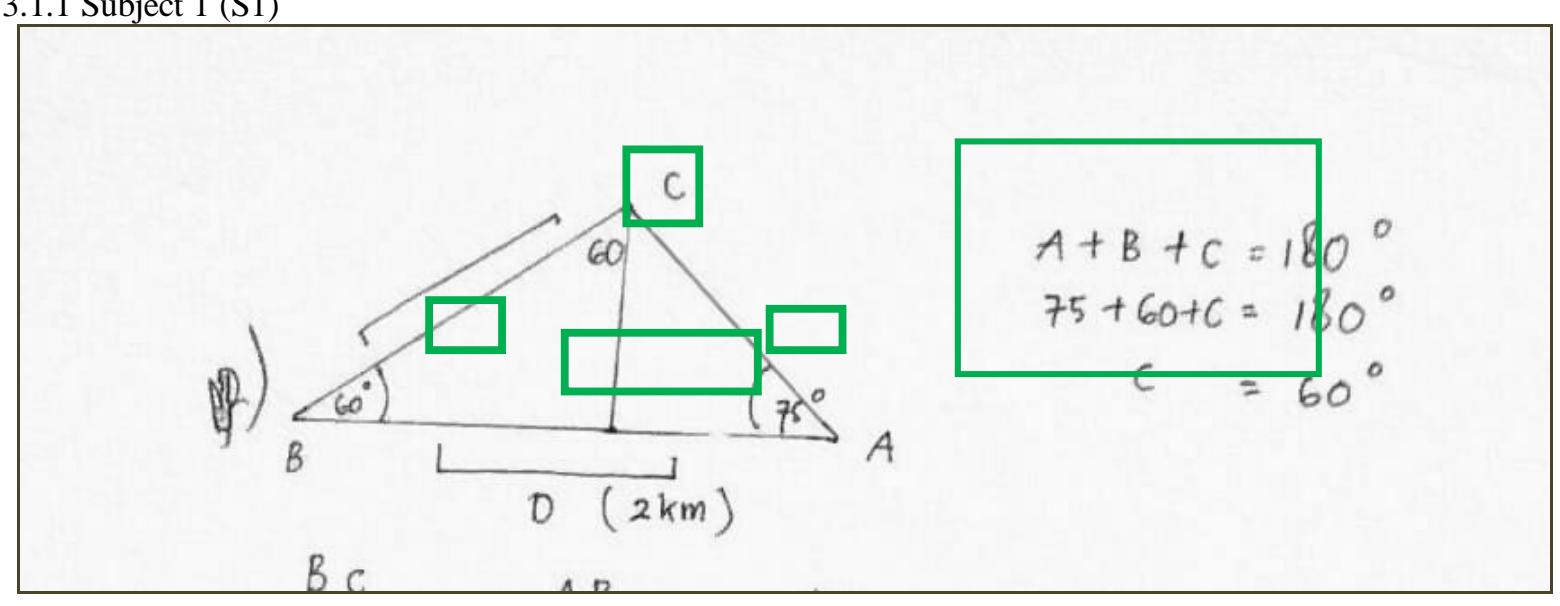

Word use

Figure 2. Word use that used by S1

Subject 1 uses word use but writes what is known to be incomplete and inaccurate and S1 does not write what is asked. The mistake made by $\mathrm{S} 1$ is writing $\angle B$ with large angles $60^{\circ}$, so $\mathrm{S} 1$ is also wrong in writing and as an explanation in the picture, subject 1 writes $\angle A=75, \angle B=60, \angle C=60$ and also the $\mathrm{AB}$ line $=2 \mathrm{~km}$. Visiual mediator

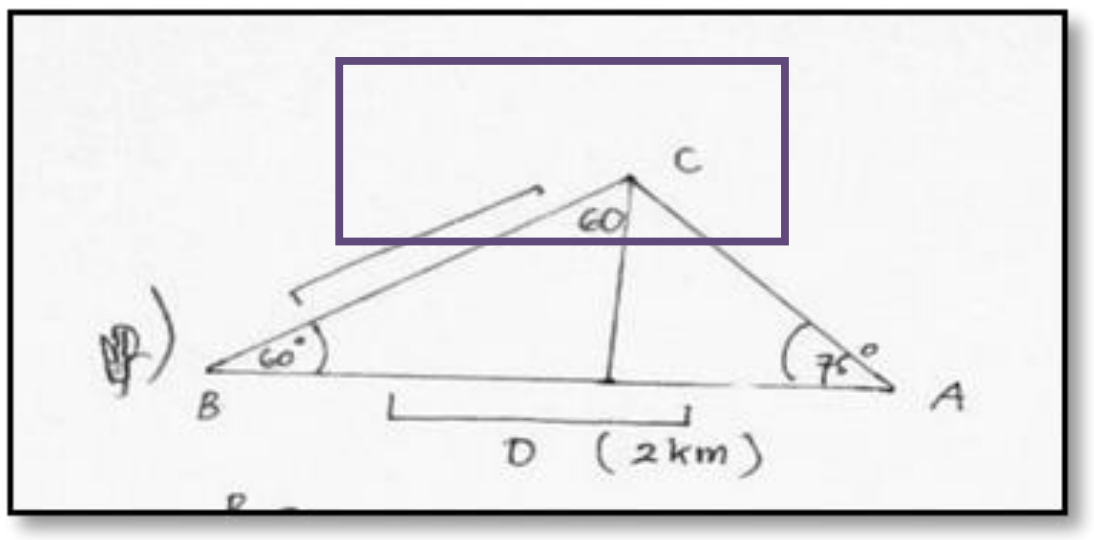

Figure 3. Visual mediator used by $\mathrm{S} 1$

Error by S1 in word use continues until the visual mediator, S1 describes the visual mediator by illustrating the problem with a triangle. In figure $3 \mathrm{~S} 1$ draws a triangle $\mathrm{ABC}$ but does not explain the line drawn from point $\mathrm{C}$ is a high line or bisector because $\mathrm{S} 1$ does not provide a perpendicular or a sign for the image.

Narratives 


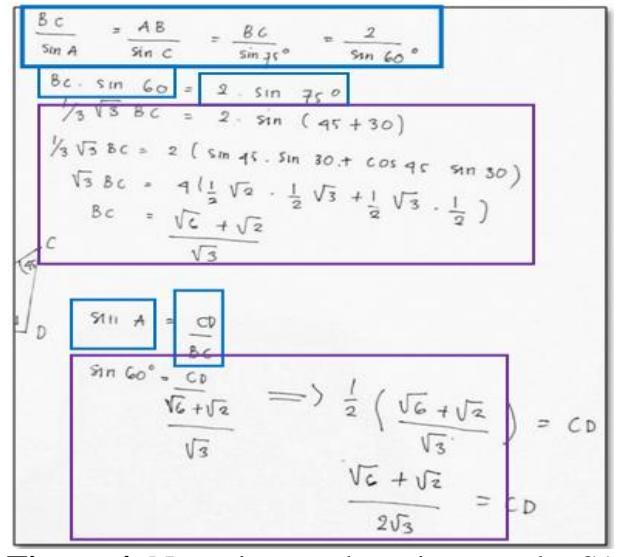

Figure 4. Narratives and routines use by $\mathrm{S} 1$

In solving problems, $\mathrm{S} 1$ begins by using the sine rule formula to determine the length of the $\mathrm{BC}$ side, namely $\frac{B C}{\sin A}=\frac{A B}{\sin C}$. after that $\mathrm{S} 1$ determines the length of the side of the CD by using the sine definition namely $\sin \alpha=\frac{\operatorname{sfront} \text { ) }}{\text { (angle) }}$ but $\mathrm{S} 1$ made a mistake in determining the length of the side of the CD by writing it down $\sin A=\frac{C D(\text { front })}{B C \text { (angle) })}$ so that clarification was made to $S 1$ in its mistake to write the formula for the definition of sine, subject 1 made the mistake because S1 was inaccurate but after being clarified it turned out that S1 understood very well about the definition of sine

$P:$ why in determining which side of the $C D$ to use the $\sin A=\frac{C D}{B C}$

Subject1:iyes, because the formula

formula of $\sin =\frac{\text { front }}{\text { angle }}$

P: so how about that $\sin A$ ?

Subject 1 : because $\sin A=\frac{C D}{A C}$ but that's right I'm looking for $B C$ side length so don't use

$P$ : Does that mean yours is wrong?

Subject 1 : yes I am not thorough

\section{Routine}

S1 uses a routine with a completion strategy that was chosen in the previous step, subject 1 substitutes the length of $\mathrm{AB}$, the angle of $\mathrm{A}$ and the angle of $\mathrm{B}$ in the sine formula and performs a computational operation but in the process of determining the $\mathrm{BC}$ side length subject 1 makes a mistake in determining the angle $\sin 30$ and $\cos 45$ so that the calculation operation error occurs. so as to produce the BC side length namely $\frac{\sqrt{6}+\sqrt{2}}{\sqrt{3}}$ After that subject 1 substitutes the length of the $\mathrm{BC}$ side $=\frac{\sqrt{6}+\sqrt{2}}{\sqrt{3}}$ in the sine definition formula and subject 1 made a mistake that continued from the Narratives stage by incorrectly substituting large $\angle A$

3.1.2. Subject 2 (S2)

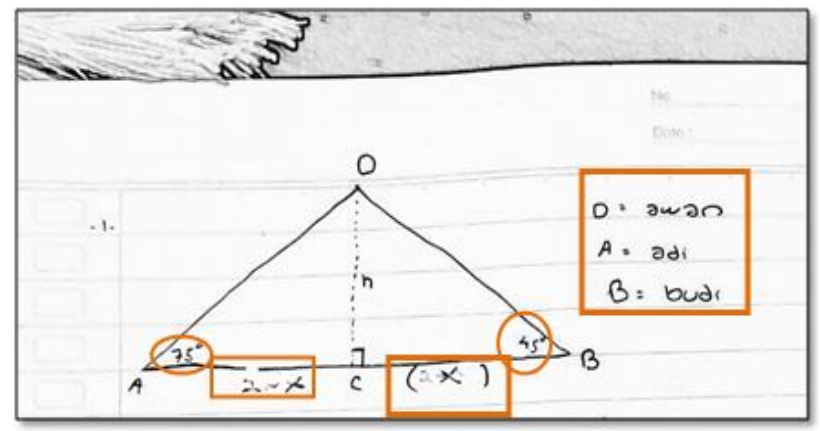

Word use

Figure 4. Word use that use by S2 
In writing the word use Subject 2 write it well, the subject writes the naming with $\mathrm{D}=$ cloud, $\mathrm{A}=\mathrm{Adi}$ and $\mathrm{B}=$ Budi, and as a description of the subject subject 2 writes $A C=2-x$ dan $C B=x$ and suppose $D C=h$ and subject 2 also writes $\angle \mathrm{A}=75^{\circ}$ dan $\angle \mathrm{B}=45^{\circ}$

Visual mediator

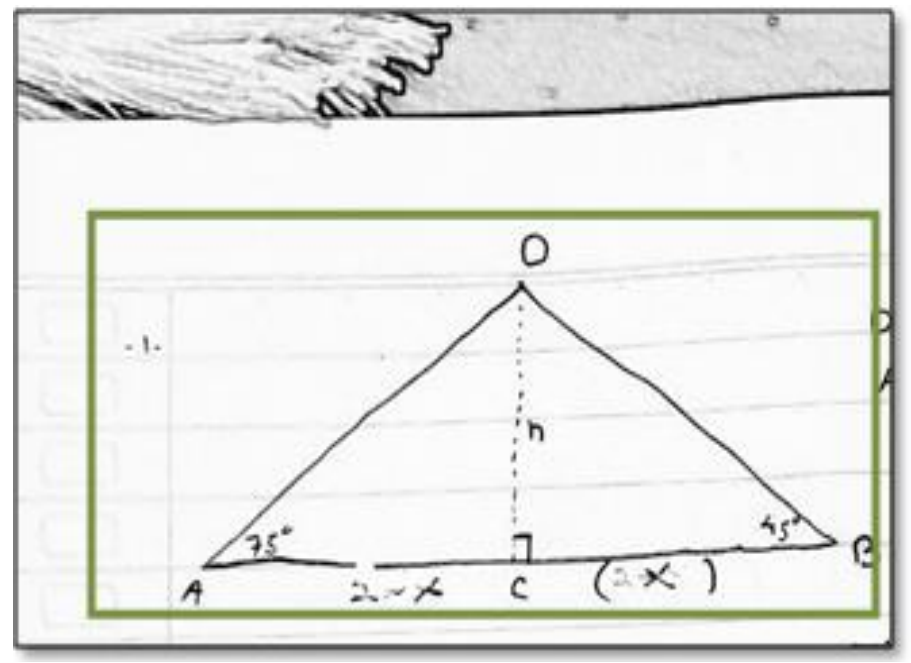

Figure 5. Visual mediator use by $\mathrm{S} 2$

Subject 2 uses a visual mediator with illustrations of problems using pictures that are triangles, subject 2 illustrates the triangle incorrectly because after clarification subject 2 only draws triangles at random without estimating the magnitude of the angles on the triangle. As well as subject 2 draw a high line from cutting the straight line $\mathrm{AB}$.

Narratives

In solving the problem of Subject 2 using the trigonometric formula of the number in tan to find the magnitude of $\tan 75$, but subject 2 did not write the formula tan the number and after that subject 2 used the definition of $\tan 75$ to find the value of $\mathrm{h}$ where $\mathrm{h}$ is the DC line after that subject 2 looks for the value $\mathrm{x}$ uses the definition of $\tan \mathrm{B}$.

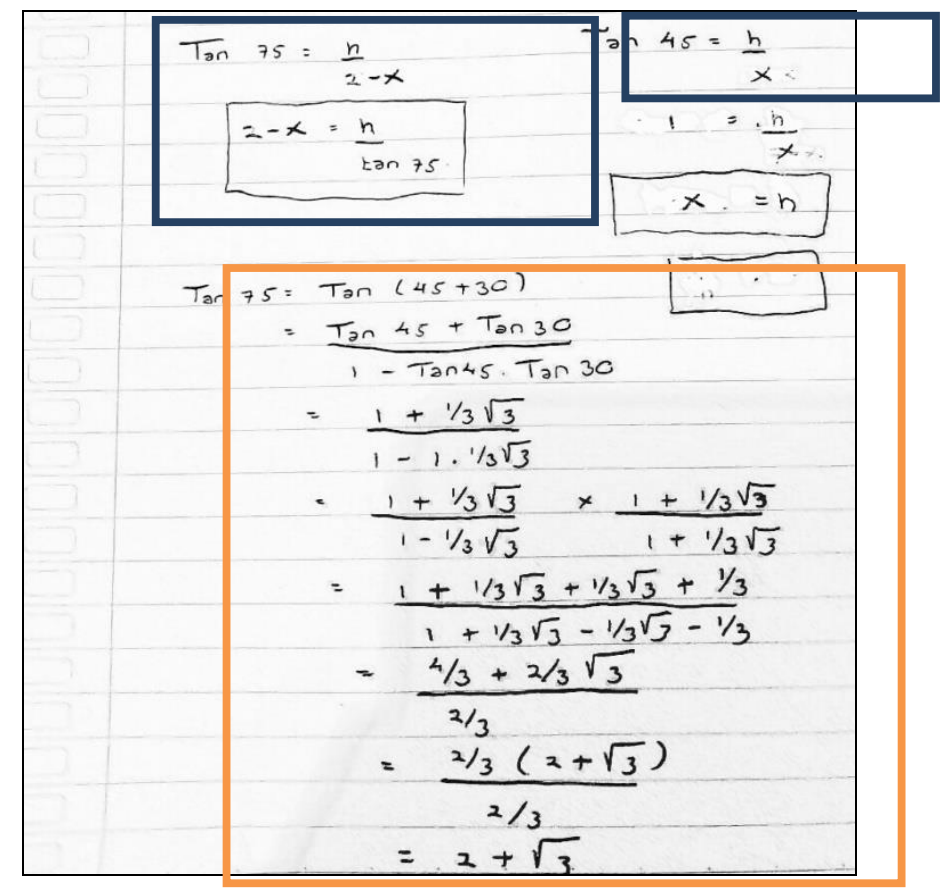

Gambar 6. Narratives and Routine use by S2 


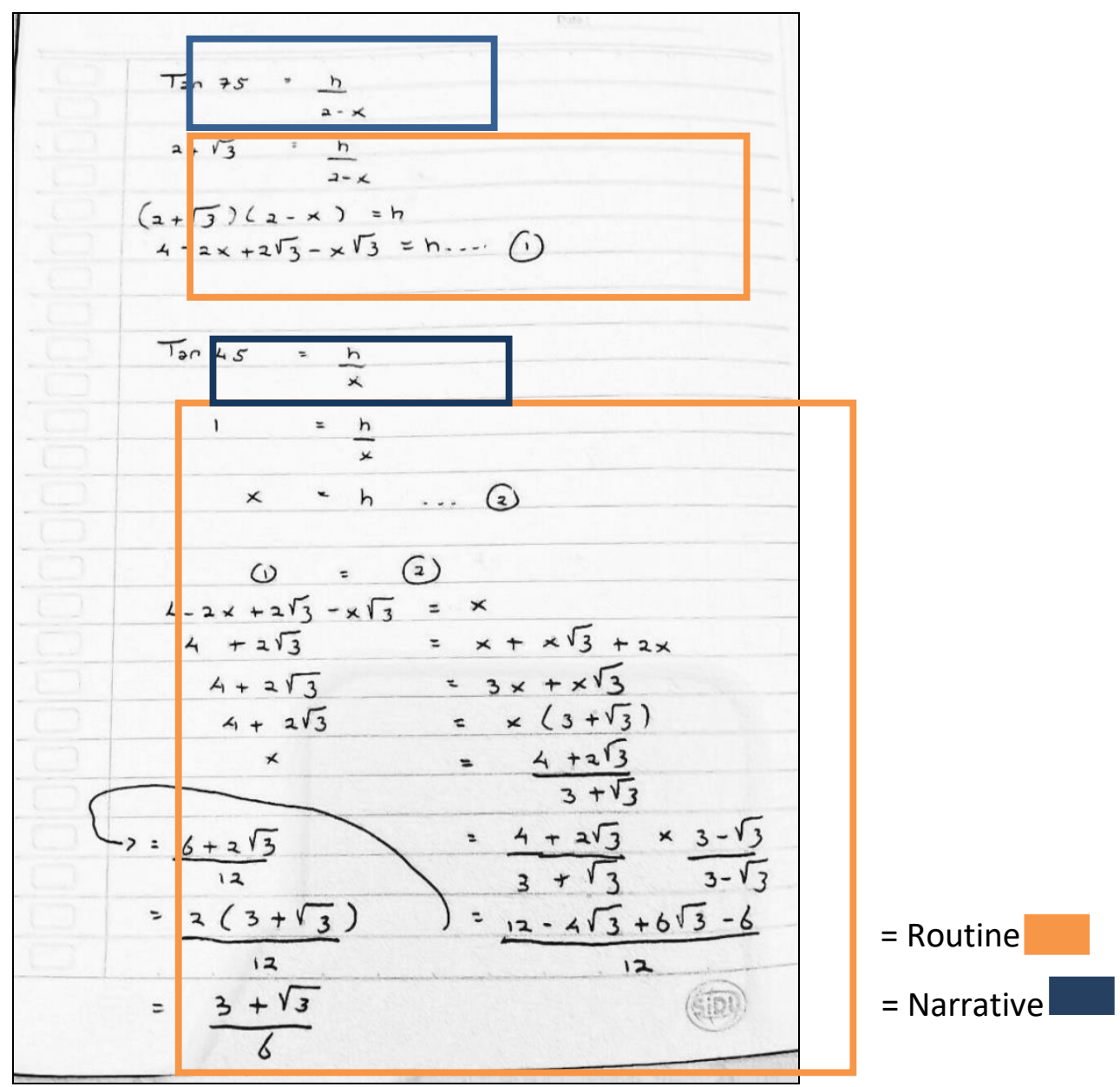

Figure 7. Narrative and routine use by S2

\section{Routine}

Subject 2 substitutes the number known in the formula by substituting the tan value 45 and tan value 30 in the trigonometric formula the number so $\tan 75=2+\sqrt{3}$ after that subject 2 substitutes values $2+\sqrt{3}$ to find $\mathrm{h}$, and subject 2 substitutes the magnitude of angle 45 at $\tan 45$ so that it produces an equation $\mathrm{x}=\mathrm{h}$ and starts to substitute the value of $\mathrm{x}$ and $\mathrm{h}$ that were sought in the previous stage but at this stage subject 2 is wrong in multiplying the denominator $\left(3+\sqrt{3)}(3-\sqrt{3})=12\right.$ so the value of $x$ on subject 2 yields $\frac{3+\sqrt{3}}{6}$

\subsubsection{Subject 3}

Word use

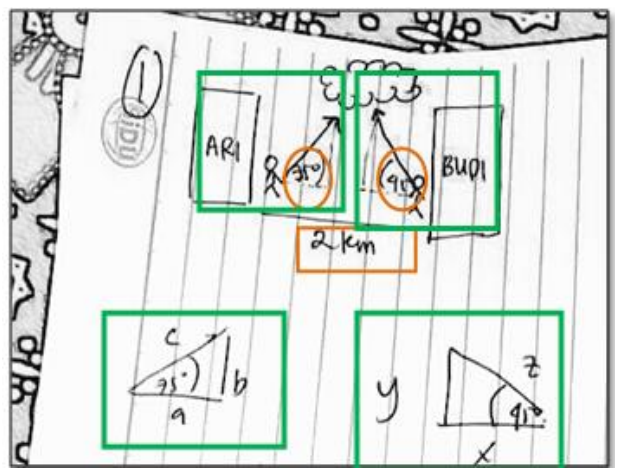

$=$ word use

= visual mediator

Subject 3 uses word use well by writing the known but not writing what is asked, subject 3 writes the angle formed Ari $=75$ and Budi's angle 45 and Ari and Budi's distance is $2 \mathrm{~km}$ and $\mathrm{a}+\mathrm{x}=2 \mathrm{~km}$.

Visual mediator 
Subject 3 uses visual mediator well, which illustrates the problem so that it appears in the picture above, the sketch made by subject 3 is two triangles that have their respective angles $75^{\circ}$ and $45^{\circ}$ Narratives

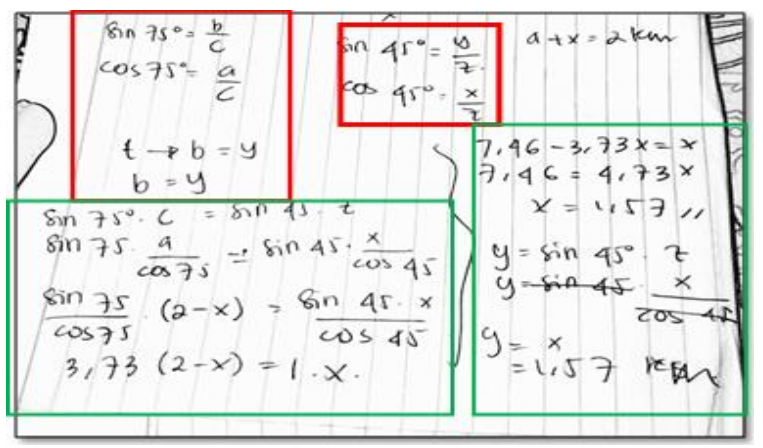

Figure 9. Narratives and routine use by S3

To solve problem 3 Subject 3 use definition of $\sin 75=\frac{b}{c}$ to know to side $\mathrm{B}$ and $\cos 75=\frac{a}{c}$ to know the $\mathrm{c}$ side as well $\sin 45=\frac{y}{z}$ to find out the $\mathrm{y}$ side and $\cos 45^{\circ}=\frac{x}{z}$ to find the $\mathrm{x}$ side and $\cos$ angle 45 to find the $\mathrm{z}$ side after that subject $\stackrel{z}{3}$ uses the equation $\mathrm{b}=\mathrm{y}$ to find the value of $\mathrm{x}$ where $\mathrm{b}$ and $\mathrm{y}$ are high lines and after knowing the value $x=1,57$ subject 3 looks for line y so that it produces $y=x=1,57$

\section{Routine}

Subject 3 substitutes $\sin 75 . c=b$ and $\sin 45 \cdot z=y$ thye equation $b=y$ so that $\sin 75 . c=\sin 45 . z$ after substitutes the $c=\frac{a}{\cos 75}$ and $z=\frac{x}{\cos 75}$ to the equation $\sin 75 . c=\sin 45 . z$ so that become $\sin 75 \cdot \frac{a}{\cos 75}=\sin 45 \cdot \frac{x}{\cos 75}$ and subject 3 changes the value of a $=2-\mathrm{x}$ where in the word use stage subject 3 writes $\mathrm{a}+\mathrm{x}=2$ after which subject 3 knows the value $x=1,57$ and the final step subject 3 substitutes the known $\mathrm{x}$ value in the equation $y=\sin 45 z$ to find out the value of $\mathrm{y}$ that is asked about the problem and replace it to be $\frac{x}{\cos 75}$ so the result $y=x$ is $y=x=1,57$

3.2 Problem 2

3.1.2 Subject 1

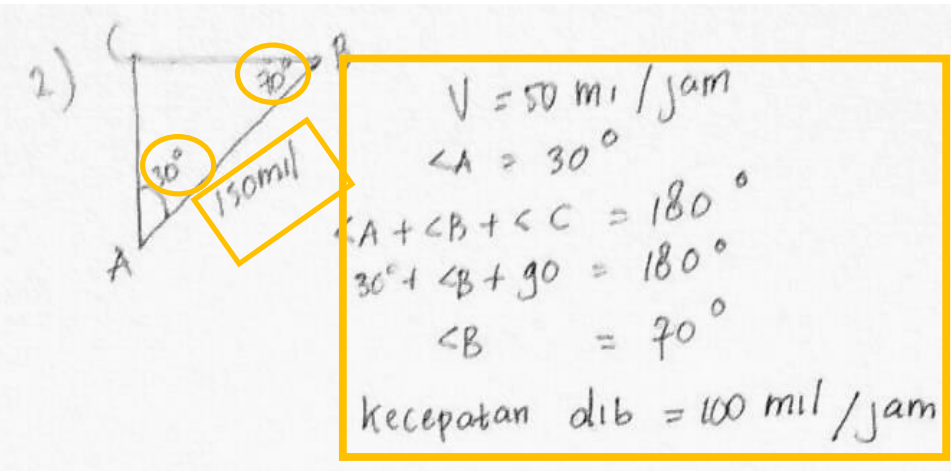

Figure 10. Word use by S1

Word use

In this second problem, subject 1 writes the known but not the question asked. The first subject 1 writes the speed symbol with the symbol $\mathrm{V}=50$ miles / hour but in naming the speed in B subject 1 no longer uses the symbol V but writes as usual "speed in B", the second subject 1 made a mistake to write the symbol angle, symbol written by subject 1 is a symbol of the sign "less than" and the third subject 1 is also wrong in writing $\angle B=70$ and the last as a description in the subject 1 picture also write down $\angle A=30, \angle B=70$ side length $\mathrm{AB}=150$ miles.

b. Visual mediator 


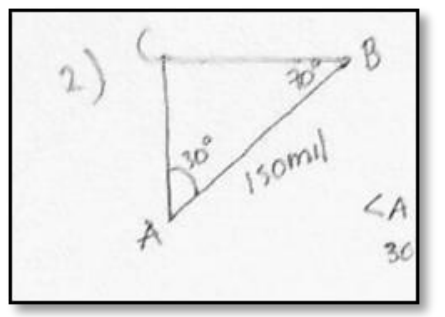

Figure 11. Visual mediator use by S1

The subject 1 error in word use continues on the visual mediator, Subject 1 writes the visual mediator by illustrating the problem with a picture that is a triangle but subject 1 does not give a perpendicular sign to the illustration of the picture because it made a mistake in the previous stage

Narratives

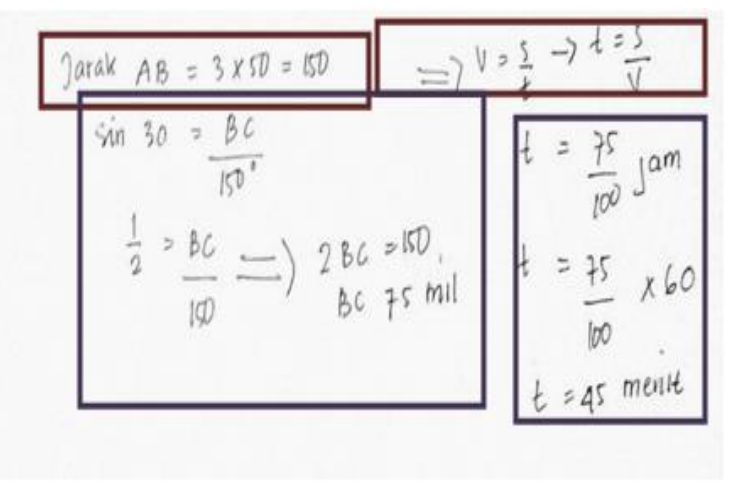

Figure 12. Narratives and routine use by $\mathrm{S} 1$

First, in solving problem 1, subject 1 uses the speed formula to determine AB distance, but subject 1 does not write the formula. after that subject 1 uses the sine definition to determine the $\mathrm{BC}$ distance and again subject 1 does not write the sine definition formula used, subject 1 immediately writes $\sin 30=\frac{B C}{150}$ after clarification, it turns out that subject 1 understood very well about the two formulas but forgot to write them down and the second after finding the distance $\mathrm{BC}$ subject 1 searched for the time taken from $\mathrm{B}$ to $\mathrm{C}$ to write the speed formula $v=\frac{s}{t}$ but at this stage subject 1 wrote the formula

P: Looking for the distance from A to B, how can it be 150 miles?

Subject 1: Yes, the time taken is 3 hours and the speed is 50 miles per hour. just multiply 3 and 50. That's the speed formula.
$P$ :
Which
speed
formula?

Subject 1: it's distance divided by time.

$P$ : You're looking for distance A to B, why don't you use the speed formula and don't use the distance formula? Subject 1 : If you want to find the distance, then you only need to speed with time.P: For $\sin 30=\frac{B C}{150}$ Where do you get

Subject 1: Oh, if that one uses the formula sin $=\frac{\text { front }}{\text { angle }}$ because what I'm looking for is long BC so use $\sin A=\frac{B C}{A B}$

$P:$ Why doesn't it write?

Subject 1: yes, I forgot.

\section{Routine}

Subject 1 uses routines by implementing the chosen strategy, namely substituting known numbers to find the $\mathrm{BC}$ distance, subject 1 substitution $A B=150$ however subject 1 writes using the degree symbol instead of miles after BC it is known that subject 1 searches for travel time $\mathrm{B}$ to $\mathrm{C}$ by substituting in the speed formula and finally subject 1 changes $t$ from units of hour To units of minutes by multiplying $t=\frac{75}{100}$ hours $x 60$ so that $t=45$ mimutes.

\subsubsection{Subject 2}




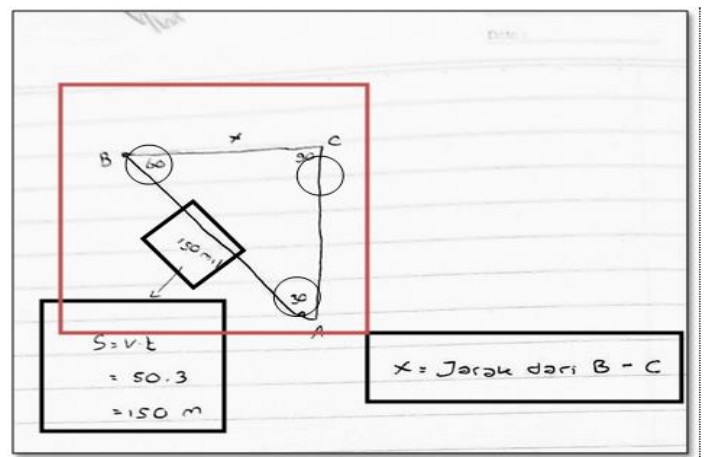

Word use

Figure 13. Word use and visual mediator use by subject 2

Subject 2 uses word use well, namely by specifying $\mathrm{x}=$ distance from $\mathrm{B}$ to $\mathrm{C}$ and writing the formula distance $\mathrm{A}$ to $\mathrm{B}$, as well as captions in the picture Subject 2 writes large $\angle \mathrm{A}=30^{\circ}, \angle \mathrm{B}=60^{\circ}$ dan $\angle C=90^{\circ}$ and $\mathrm{AB}$ $=150$ miles.

Visual mediator

Subject 2 uses the visual mediator well, that is, subject 2 illustrates the problem in the picture that is a right angle even though subject 2 did not draw it using a ruler

Narratives

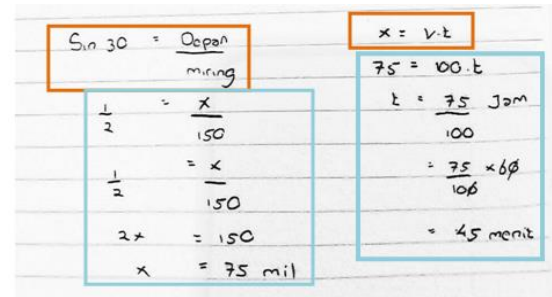

Figure 14. Narrative and Routine use by $\mathrm{S} 2$

Subject 2 uses the sine definition formula that is sake (oblique front) to find the value of $\mathrm{x}$ where $\mathrm{x}$ is the distance $\mathrm{B}$ to $\mathrm{C}$ after that Subject 2 uses $\mathrm{x}$ to find the required travel time from $\mathrm{B}$ to $\mathrm{C}$ using the formula speed $\mathrm{x}$ $=\mathrm{v}$. $\mathrm{t}$ then subject 2 changes the unit from hour to minute by multiplying it by 60 .

Routine

Subject 2 substitutes the numbers known in the sine formula to find $\mathrm{x}$, which is to write sin 30 by and replace the front edge of angle 30 by $x$ and the hypotenuse by 150 so that subject 2 finds $x=75$ miles after that subject 2 searches for travel time by substituting $x=75$ and $v=100$ so it produces $t=\frac{75}{100}$ hours but because the question asked is minutes, subject 2 converts it into units of minutes so that the resulting time takes 45 minutes. 3.2.3 Subject 3

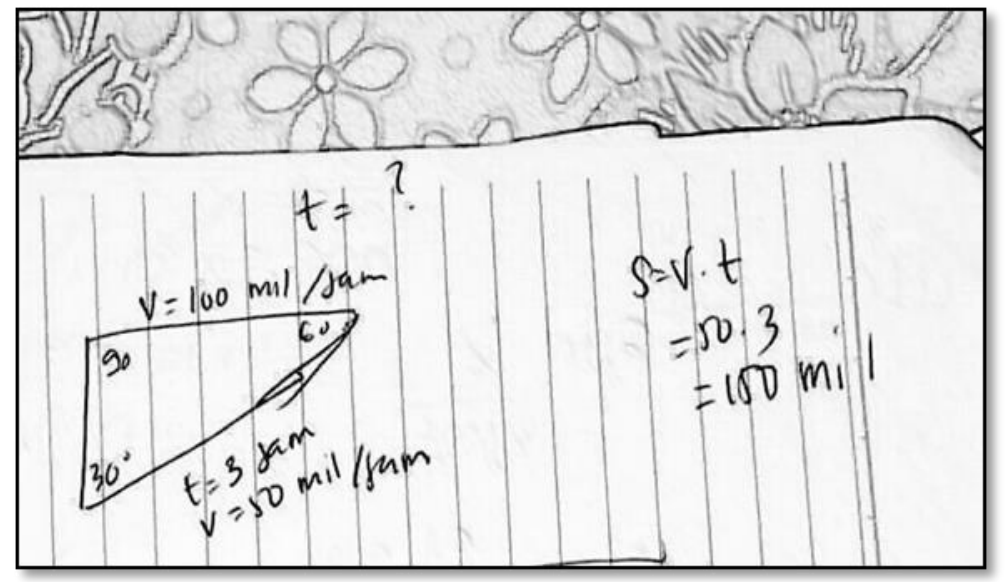

Word use

Figure 15. Word use and visual mediator use by S3

Subject 3 uses word use well that is writing known and asked, subject 3 writes $s=150$ miles as explanation on Gambar subjek 3 menuliskan $V=100 \frac{\text { miles }}{\text { hour }}, t=3$ hours, $V=50 \frac{\text { miles }}{\text { howr }}$ and write down the angle at each 
point of the triangle, respectively $90^{\circ}, 30^{\circ}$ and $60^{\circ}$ and also subject 3 write what is asked with symbols $t$ (time)

Visual mediator

Subject 3 uses visual mediator well to make it easier to work on the problem by illustrating the problem with the picture and sketching it according to the provisions in the problem, but at this stage subject 3 sketches the image without using a ruler

Narrative

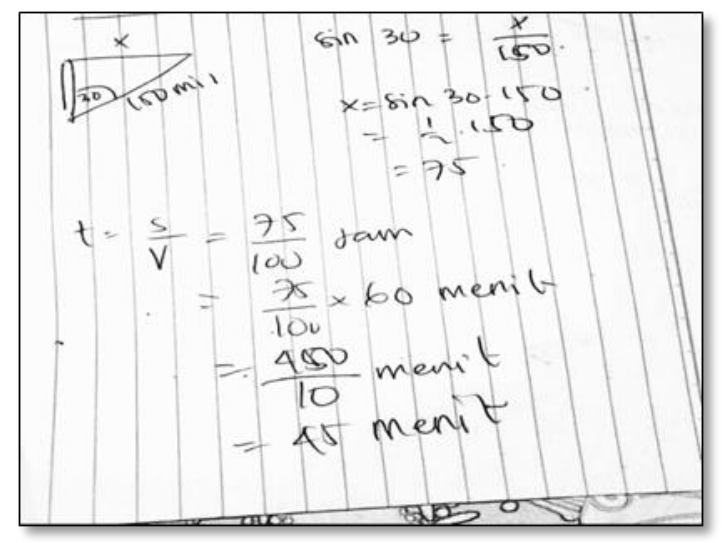

Figure 16. Narrative and Routine use by $\mathrm{S} 3$

In solving the problem subject 3 uses the definition of sine to determine the value of $\mathrm{x}$ by writing $\sin 30=\frac{x}{150}$ after the value of $\mathrm{x}$ is known subject 3 looks for $\mathrm{t}$ by using $t=\frac{s}{t}$ and change the unit $\mathrm{t}$ hour by multiplying 60.

Routine

Subject 3 substitutes the known value in the formula by substituting $\sin 30=\frac{1}{2}$ to determine the value of $\mathrm{x}$ such that $x=75$ miles after that subject 3 substitutes values $x=s=75$ miles and $v=100$ to formula $t=\frac{s}{v}$ so the final value is found $t=\frac{75}{100}$ hours and finally subject 3 changes the unit of hours to minutes by multiplying thours by 60 such that $t=45$ minutes.

\section{Discussion}

The results of this study describe the mistakes of class $\mathrm{X}$ students in solving high order thinking skills trigonometry material. This student error was obtained from the results of a math problem sheet and an interview. The following will be discussed based on the cognitive frameworks namely Word use, Visual Mediator, Narrative, and Routine:

Word use

Student mistakes in solving problems occur because students are using word use properly and completely. There are habits of students in solving problems without writing down what is known and asked but students can solve the problems given (Carson, 2007). As for the mistakes of some students in using word use, which is wrong in writing mathematical symbols, inconsistent in writing naming, wrong in writing a value, this is consistent with the claims of Hoch and Dreyfus (2004) that there is no correlation between student structure and manipulation skills. this agrees with this case because students are not careful in reading the questions. The factors that cause students to mistake in working on story problems are hasty, inaccurate, not understanding the questions, incomplete writing is known, and asked, not understanding the material (Nurussafa'at,et al., 2016).

Visual mediator

Student mistakes in solving problems occur because one of them is not using visual mediators, visual mediators will make it easier for students to solve problems with the help of illustrating problems in the form of images so that will minimize the occurrence of errors, but some students use visual mediators but are still wrong and use it, the first is some students' mistakes occur because students do not write perpendicular marks on the triangle that has so that the triangles drawn by students will be confused between random triangles and right angles elbows, and students also misrepresent triangles because they draw triangles incorrectly, students draw triangles without estimating the magnitude of each angle on the triangle. Widdiharto (2008: 41) states that careless work done by students when solving mathematical problems causes errors in the work process.

Narrative

Student mistakes in solving problems also occur because students do not know the strategy that will be used to solve them, while the students' mistakes made at this stage are: students are wrong in writing the formula 
definition sine and wrong for not writing the formula. This is following the opinion namely procedural errors are errors in compiling systematic hierarchical steps to answer a problem (Mulyana, et al., 2019)

Routine

After determining the strategy chosen by students in completing the questions students carry out the chosen strategy, this shows the Routine that students do. The mistakes of some students in general in doing routine are the students doing wrong calculations, wrong in substituting values or numbers that are known in the formula. Strengthened by Reid's research results in (Jamaris, M., 2013: 186) said that the characteristics of children who have difficulty learning mathematics are characterized by the inability to solve problems related to aspects of understanding in the process of grouping, adding and subtracting, visual perception, perception auditory, calculate, and transfer knowledge. Students are less careful in counting and students are wrong in counting due to haste (Powell \& Fuchs. 2012).

\section{Conclusion}

Based on the results of the analysis and discussion, students' mistakes in solving trigonometric problems based on 4 frameworks are as follows 1). Word use in the form of student errors in writing mathematical symbols, inconsistent in writing the naming of symbols, writing the known but not those asked. 2) visual mediator in the form of student error in drawing random origin confusing 3). Narrative in the form of an error does not write the formula first but goes directly to the counting phase 4) Routine in the form of a student error in performing a count operation. By analyzing students' mistakes the teacher can find out the location of difficulties and misconceptions of students in doing so that it becomes new learning for students to improve learning outcomes and minimize errors. with mistakes analysis with a commognitive point of view provides an overview of thinking and communication of some error analysis in solving mathematical problems.

\section{References}

1. Acharya, B. R. (2017). Factors affecting difficulties in learning mathematics by mathematics learners. International Journal of Elementary Education, 6(2), 8-15.

2. Arif, S. (2019). Higher Order Thinking Skills (HOTS) Analysis on Teachers's Questions in the Final Examination of Bahasa dan Sastra Indonesia at Senior High School 7 Medan. Budapest International Research and Critics in Linguistics and Education (BirLE) Journal, 2(4), 172-178.

3. Berger, M. (2013). Examining mathematical discourse to understand in-service teachers' mathematical activities. Pythagoras, 34 (1), 1-10. https://doi.org/10.4102/pythagoras.v34i1.197.

4. Carson, J. (2007). A problem with problem solving: Teaching thinking without teaching knowledge. The mathematics educator, 17(2).

5. Hossain, M. I. (2015). Teaching productive skills to the students: a secondary level scenario (Doctoral dissertation, BRAC University).

6. Karimah, R. K. N., Kusmayadi, T. A., \& Pramudya, I. (2018). Analysis of difficulties in mathematics learning on students with guardian personality type in problem-solving HOTS geometry test. In Journal of Physics: Conference Series (Vol. 1008, No. 1, p. 012076). IOP Publishing.

7. Kurniati, D., \& Zayyadi, M. (2018). The critical thinking dispositions of students around coffee plantation area in solving algebraic problems. International Journal of Engineering \& Technology, 7(2.10), 18-20.

8. Li, Y., Schoenfeld, A.H. (2019). Problematizing teaching and learning mathematics as "given" in STEM education. IJ STEM Ed 6, 44. https://doi.org/10.1186/s40594-019-0197-9

9. Mulyana, T., Amin, S. M., \& YES, T. (2019). Error Analysis of Class V Students in Resolving Decimal Fractional Division. International Journal of Innovative Science and Research Technology. 4(12). 982-987.

10. National Council of Teachers of Mathematics. (2000). Principles and Standards for School Mathematics. VA: NCTM Inc.

11. Nardi, E., Ryve, A., Stadler, E., \& Viirman, O. (2014). Commognitive analyses of the learning and teaching of mathematics at university level: The case of discursive shifts in the study of Calculus. Research in Mathematics Education, 16(2), 182-198. https://doi.org/10.1080/14794802.2014.918338.

12. Nurussafa'at, F. A., Sujadi, I., \& Riyadi, R. (2016). Analysis of Student Errors in Completing Story Questions on Prism Volume Material with Fong's Shcematic Model For Error Analysis in terms of Student Cognitive Style. Jurnal Elektronik Pembelajaran Matematika, 4(2); 174-187.

13. Powell, S. R., \& Fuchs, L. S. (2012). Early numerical competencies and students with mathematics difficulty. Focus on exceptional children, 44(5), 1.

14. Presmeg, N. (2016). Commognition as a lens for research. Educational Studies in Mathematics. https://doi.org/10.1007/s10649-015-9676-1. 
15. Saragih, S., \& Habeahan, W. L. (2014). The improving of problem solving ability and students' creativity mathematical by using problem based learning in SMP Negeri 2 Siantar. Journal of Education and Practice, 5(35), 123-133.

16. Sfard, A. (2007). When the rules of discourse change, but nobody tells you: Making sense of mathematics learning from a commognitive standpoint. Journal of the Learning Sciences, 16(4), 565613. https://doi.org/10.1080/10508400701525253

17. Sfard, A. (2008). Thinking as Communicating: human development, the growth of discourses, and mathematizing. Cambridge Universiti Press: New York.

18. Sfard, A. (2018). Anna Sfard Department of Mathematics Education, University of Haifa, Haifa, Israel. $1-7$.

19. Sipayung, T. N., \& Anzelina, D. (2019). An analysis of students problem solving skills using a realistic mathematics approach on integers materials. In Journal of Physics: Conference Series (Vol. 1211, No. 1, p. 012083). IOP Publishing.

20. Subanji. (2015). Improved Pedagogical Content Knowledge for Mathematics Teachers and Their Practices in Learning through the TEQIP Training Model. Jurnal Ilmu Pendidikan, 21(1). 71 - 79.

21. Sullivan, P. (2011). Teaching Mathematics: Using Research-Informed Strategies. Australian: ACER Press.

22. Zayyadi, M., Nusantara, T., Subanji,. Hidayanto. E, \& Sulandra, I. M. (2019). A Commognitive Framework: The Process of Solving Mathematical Problems of Middle School Students. International Journal of Learning, Teaching and Educational Research, 18(2), 89-102.

23. Zayyadi, M., Nusantara, T., Hidayanto, E., Sulandra, I. M., \& Sa'dijah, C. (2020). Content and Pedagogical Knowledge of Prospective Teachers in Mathematics Learning: Commognitive Framework. Journal for the Education of Gifted Young Scientists, 8(1), 515-532. 